Ariane Berger

\title{
Die Ordnung der Aufgaben im Staat
}

Zum Verfassungsgrundsatz getrennter Verwaltungsaufgaben

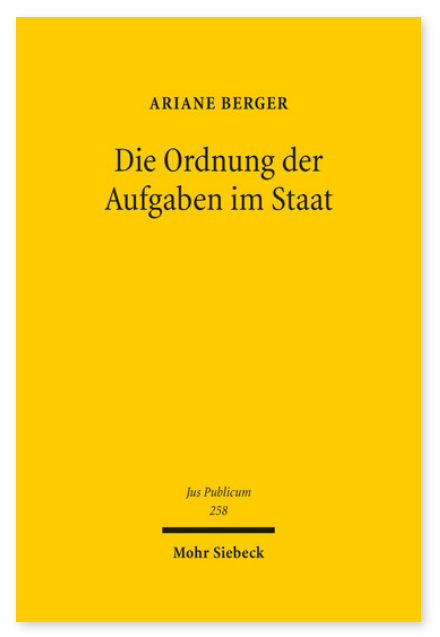

2016. XIII, 370 Seiten. JusPubl 258

ISBN 978-3-16-154868-0

DOI 10.1628/978-3-16-154868-0

eBook PDF 104,00€

ISBN 978-3-16-154808-6

Leinen $104,00 €$
Die Aufgaben der deutschen Verwaltung sind nicht zuletzt aufgrund föderaler, unionaler und internationaler Vorgaben vielfältig miteinander verflochten. Angesichts dieses Befundes stellt sich die Frage, ob der Ordnung der Aufgaben im Staat ein bestimmtes verfassungsrechtliches Modell zugrunde liegt. Ariane Berger bestimmt die verfassungsrechtlichen Komponenten einer solchen Aufgabenordnung und definiert als verfassungsrechtliches Ordnungsmodell die Idee des einen richtigen Entscheidungssubjektes. Auf seiner Grundlage entfaltet sie die Anforderungen an eine punktgenaue, parzellenscharfe und arbeitsteilige Aufgabenordnung, die der Gesetzgeber bei der Ausgestaltung der Aufgabenordnung beachten muss. Ob und inwieweit die gesetzliche Ausgestaltung diesen Anforderungen genügt, untersucht die Autorin anhand verschiedener nationaler, unionaler sowie internationaler Aufgabenverflechtungen der Verwaltung.

Ariane Berger Geboren 1978; Studium der Rechtswissenschaft; 2005 Promotion; seit 2007 Wissenschaftliche Mitarbeiterin an der Freien Universität Berlin; seit 2015 Lehrstuhlvertretungen an der Ludwig-Maximilians-Universität München und der Humboldt-Universität zu Berlin; 2016 Habilitation.

Jetzt bestellen:

https://mohrsiebeck.com/buch/die-ordnung-der-aufgaben-im-staat-9783161548680?no_cache=1 order@mohrsiebeck.com

Telefon: $+49(0) 7071-923-17$

Telefax: $+49(0) 7071-51104$ 